\title{
The Essential Three (e3): A University Partnership to Meet the Professional Learning Needs of Rural Schools
}

\author{
Matthew Ohlson \\ Jerry Johnson \\ Shane Shope \\ Jennifer Rivera
}

The Essential Three (e3) is a professional learning series that focuses on supporting rural school districts and school leaders as they engage in the important work of prioritizing and determining areas of instructional focus. As educators transition to new rigorous state and national standards and face the challenges of learning newly adopted instructional frameworks/evaluation tools, the e3 training has offered educators much needed guidance and support within high-needs, rural districts in Florida. As the result of a partnership between the North-East Florida Educational Consortium (NEFEC) and the University of North Florida, teacher leaders and school administrators have now implemented a streamlined process to increase rigor, collaboration, and student engagement within the learning environment. This work details the comprehensive implementation process, as well as various promising practices for educators and rural school leaders to impact policies and instructional practice.

This paper presents a retrospective account of the development, planning, and implementation of a school-based professional learning series (Essential Three or e3) that focused on supporting rural districts and school leaders as they engage in the important work of prioritizing and determining areas of instructional focus. In the context of describing that work, attention is given to the support role played by the educational service agency and the stewardship role played by the university - two critical roles/partners for schools in rural settings (Colf \& Harmon, 2011; Johnson, Thompson, \& Naugle, 2009). Attentive to the relevant literature and drawing on findings from our reflective analysis of the planning and implementation work, we extrapolate lessons about process that will inform the (still ongoing) work and should inform similar work in other rural settings.

\section{Context: Florida Policy Changes and the Role of Educational Service Agencies}

In 2014-2015, Florida adopted new standards in $\mathrm{K}-12$ education (which are a derivative of the Common Core Standards). During that same time frame, teachers and administrators were also legislatively mandated to devise new methods of evaluation and compensation. All these changes at once meant that district and school personnel were scrambling to not only adopt/adapt methods, but to secure "buy in" for new systems, new ways of work, and new ways of evaluating progress and outcomes for both students and adults. The cornerstone of all these new systems was elevated rigor.

The challenges presented by these new standards and accompanying mandates are especially pressing in rural school districts with limited staff and/or specialized capacity. Educational Service Agencies (ESAs) have been in existence in Florida since 1969 and were created to support rural districts in creating collective service agreements to help with such limitations and to encourage collaboration among practitioners (Colf \& Harmon, 2009). ESAs also provide an effective way for rural school leaders to leverage their district's limited resources, resulting in significant gains in efficiency and student support services (Stephens \& Keane, 2005). The development of this shared service approach has also reinforced the development of innovative practices that support collaborative work between researchers and educators. Over time, ESAs have transformed and, in some cases, become innovation labs providing opportunities for action research initiatives that can be tested and analyzed (Harmon, 2006). Having the ability to meet needs within the immediate context and environment of the service areas provides a model of robust financial efficiency and supporting the immediate needs of schools.

Florida's ESA system includes three agencies (Heartland Educational Consortium, North East 
Florida Educational Consortium, and Panhandle Area Educational Consortium). Each is a non-profit, non-regulatory agency that provides cooperative services to rural school districts in its geographic region. NEFEC was a key partner in developing and implementing the e3 school-based professional learning series described here. NEFEC serves nearly 78,000 students in 15 small and rural Florida school districts, with a mission to help member districts cooperatively meet their educational goals and objectives by providing programs and services that individual districts would not be able to provide as effectively or as economically when acting alone. One of the ways that NEFEC has supported this mission is through grant writing and the cultivation of positive partnerships with other entities. One such critical partnership is reflected in NEFEC's relationship with the University of North Florida (UNF).

\section{Setting and Identified Needs}

NEFEC, with fiscal agent Gilchrist County, applied for a Teacher Incentive Fund grant (Sustainable Educator Evaluation and Compensation or SEEC) in 2011 to help support the implementation of state and federal mandates that transitioned schools to implementing the Common Core Standards and prompted schools to overhaul their teacher evaluation systems. One of the key objectives of this grant is to provide professional learning to teachers and administrators related to the use of each district's teacher observation/evaluation systems as a tool for teacher instructional improvement. SEEC was viewed as a tremendous opportunity to leverage the regional assistance model that NEFEC commonly deploys, for the purpose of helping administrators and teachers provide engaging instruction that meets the demands of rigor called for by the Florida Standards Assessment (FSA). Districts needed a way to manage the work of converging all of these changes into a manageable set of tasks that would result in the improvement of teacher practice and of outcomes for students. Through their partnership with UNF, and with initial support from the Public Consulting Group (PCG), a coherent and integrated set of professional learning activities were developed and implemented to support this need.

The eight participating school districts supported by SEEC are documented high needs districts. As determined by the Florida Department of Education accountability system, these districts have earned the following academic grades for 2015 (the first year of the new state assessment in all grade levels):

Bradford County (C), Columbia County (C), Flagler County (A), Gilchrist County (A), Hamilton County (D), Lafayette County (B), Suwannee County (C), and Union County (A). In terms of achievement on the new Florida Standards for English/Language Arts (ELA) and Mathematics, five out of the eight districts earned a $50 \%$ or lower pass rate on the Florida Standards Assessment for ELA and four of the eight earned a $50 \%$ or below pass rate on the Florida Standards Assessment for Mathematics.

In addition, $16.2 \%$ of the population in these districts is reported to be living in poverty compared
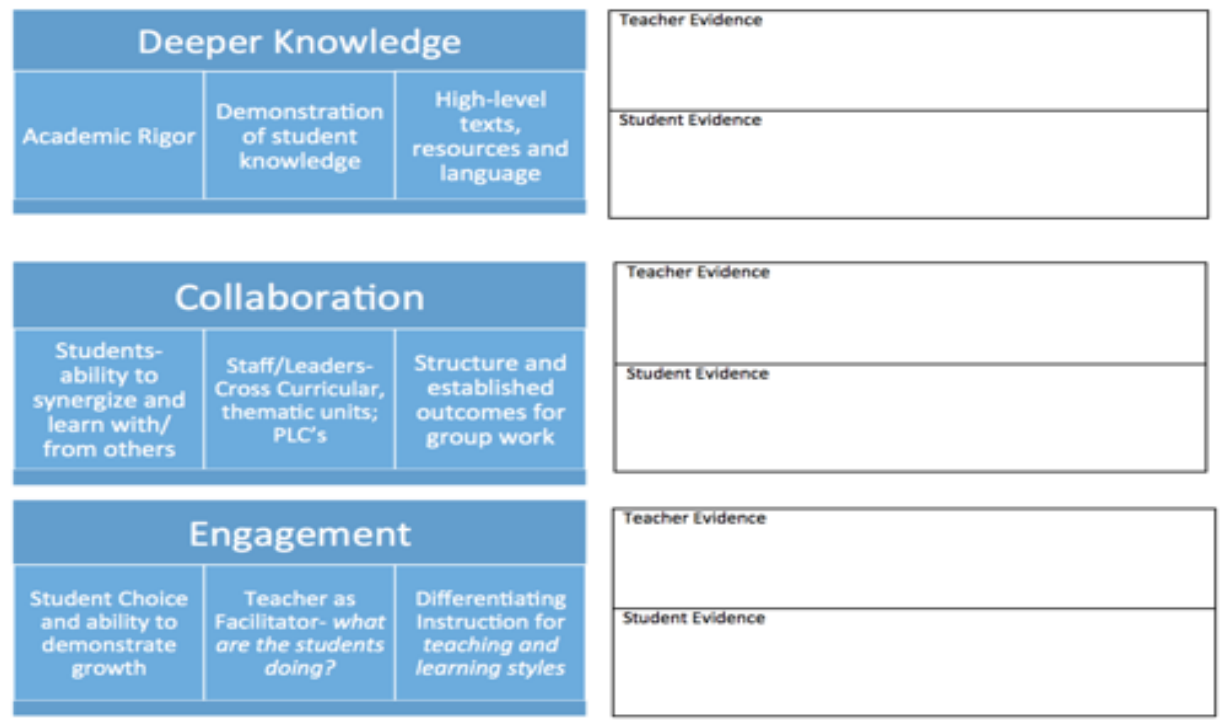
to the Florida average of $13.8 \%$ (U.S. Census of Housing and Population, 2010). In SEEC schools, $63.9 \%$ of the student population is eligible for Free/Reduced Lunch, compared to a rate of $57.6 \%$ for the state of Florida. In light of the high levels of poverty and student achievement challenges that often characterize small and rural districts, these grantees adopted a stance that they needed unique solutions to help them achieve their foundational goals, which were increased student achievement and increased teacher effectiveness. A foundational principle among these districts was the belief that highly effective teachers and leaders make the difference in student achievement.

With this objective in mind, NEFEC staff, with the assistance of UNF faculty, crafted a learning series for administrators, instructional coaches, and others who contribute to the data collected through observing and giving feedback to teacher practice. The basis of the training series was to help observers narrow the focus and field of their observations, keeping to the intent and language of the observation rubrics and evaluation matrices employed by the NEFEC districts participating in SEEC. To accomplish this, UNF faculty and the NEFEC team, with input from a team of teachers and school leaders, chose to focus observer learning on three crucial research-based areas of classroom instruction: deeper knowledge, collaboration, and engagement. The teams designated these three research-based focus areas as the Essential Three. See Figure 1.

\section{Relevant Research and Development of the $e 3$ Model}

The components of the $e 3$ model were developed on the basis of extensive research in the area of teaching and learning practices. While all areas of the district-selected instructional frameworks were deemed to be critical and valuable, districts needed an implementation plan that helped focus their attention on a few indicators. This would allow both leaders and educators to prioritize focus areas and intensively learn, implement, and provide quality feedback on a few critical areas that were present in each district's tool and foundational to teaching and mastery of the new Florida Standards during the first phase of transition.

\section{Collaboration}

Collaboration was deemed a critical area of focus in the $e 3$ model. As conceptualized in the $e 3$ model, collaboration has implications for both instruction (i.e., collaboration among students, as facilitated by the teacher) and organizational structures and systems (i.e., collaboration among educators within the school. These two types of collaboration have been shown to contribute directly (e.g., Marzano, 2007; Danielson, 2013) and indirectly (Glickman, Gordon, \& Ross-Gordon, 2017) to desirable outcomes such as increased student achievement and a positive collegial culture focused on student achievement.

Collaboration as a teaching and learning strategy is addressed throughout the Florida Standards for ELA. These new standards require students to engage in provocative conversations about texts with teachers and peers. Collaboration is also a common thread throughout both of the selected instructional frameworks used in NEFEC's TIF districts. Marzano's framework requires educators to organize students for learning, elaborate on new information, and engage students in friendly controversy, all of which require varying levels of collaboration (Marzano, 2007). Danielson's framework requires students to engage in discussions (Danielson, 2013).

Moreover, collaboration within an educational setting is a critical factor for successful improvements in teaching and learning (Macneil, Prater \& Busch, 2009). Deal \& Peterson (1999) contend that higher achieving schools demonstrated cultures that fostered collaboration, empowerment, and engagement. In contrast, schools with toxic cultures with little stakeholder collaboration were more likely to produce poor academic achievement. Leithwood and Seashore-Louis (1998) suggest that successful schools are more capable of increasing student achievement when the culture shares common characteristics including a commitment to the students, respect for shared decision making, a collective belief in the importance of professional growth, collective celebrations of success, and a mission grounded in the ideal that all students can achieve. Indeed, extensive research throughout the state of Florida found that as teacher collaboration increased, the model predicted that student suspensions would decrease by $6.709 \%$ (Ohlson, 2009).

\section{Deeper Knowledge}

The $e 3$ model's conceptualization of deeper knowledge follows the framework articulated by the William and Flora Hewlett Foundation (2012) and includes six interconnected competencies: mastering 
rigorous academic content, critical thinking and problem-solving, working collaboratively, communicating effectively, self-directed learning, and developing a growth mindset. The framework aligns with policy and practice considerations in Florida. Deeper knowledge tightly aligns with both the Marzano and Danielson (FLDOE, 2012) teacher evaluation models, which are commonly used in numerous districts throughout the state. This framework clearly supports elements such as Marzano's expectations for engaging students in cognitively complex tasks, and Danielson's expectations within multiple elements that all students demonstrate learning, among many others. Embedded within this Deeper Knowledge component are elements that focus on (1) student learning and engagement in academic rigor, (2) the demonstration of knowledge and learning, and (3) practicing with content - all with a heavy focus on the design of learning activities for student and educators learning,

The importance of deeper knowledge for students is evident in research investigating outcomes among schools that explicitly focused on cultivating deeper knowledge/deeper learning. A report by Barron \& Darling-Hammond (2008), found that "deeper learning" schools graduate high school students on time at rates nine percent higher than other schools, a win for teachers and students alike. The study they described paired 13 "deeper learning" schools, all members of Hewlett Packard's "Deeper Learning Network," with other schools that have comparable student demographics (including underserved student populations) and incoming achievement levels. Graduates of the "deeper learning" schools were over four percent more likely to enroll in four-year colleges, and they were slightly more likely to attend selective schools (AIR, 2014).

\section{Engagement}

As conceptualized in the $e 3$ model, student engagement represents the extent of students' willing involvement or interest in their learning and their connectedness to their classes, their school, and their peers (Christenson, Reschley, \& Wylie, 2013). Engagement is present in both teacher evaluation instruments. Both Marzano and Danielson models emphasize the need to move beyond rote learning and encourage critical thinking, questioning, and multiple representations of knowledge. Marzano specifically identifies Design Question five as Engaging Students (Marzano, 2007). This question is composed of indicators related to presenting information in an intriguing way, demonstrating enthusiasm and withit-ness, probing incorrect responses, and noticing and acting when students are not engaged. Danielson addresses engagement in Domain 2b: Establishing a Culture for Learning (Danielson, 2013).

Engagement was identified as a critical focus based on a consistent body of research reporting that higher levels of engagement are associated with better rates of attendance, higher academic achievement levels, fewer disciplinary incidents, lower dropout and grade retention rates, and higher graduation rates (Appleton, Christenson, \& Furlong, 2008; Finn, 1989; Finn, 1993; Fredricks, Blumenfeld, \& Paris, 2004; Jimerson, Campos, \& Grief, 2003; Jimerson, Renshaw, Stewart, Hart, \& O’Malley, 2009; Shernoff \& Schmidt, 2008). In contrast; students with low levels of engagement are at risk for a variety of long-term adverse consequences, including disruptive behavior in class, absenteeism, and dropping out of school. Further supporting engagement as an area focus is evidence that engagement is a malleable factor amenable to influence by teacher and leader practice (Klem \& Connell, 2004; Railsback, 2004).

\section{e3 Implementation}

Informed by the above-described salient literature and attentive to the roles of the ESA (NEFEC) and university (UNF) partners, the professional learning series around the e3 model began during the 2014-2015 school year with an introduction for both principals and instructional coaches. The decision was made early on to include both administrators and coaches in the series in order to provide specific coaching strategies that were mutually applicable to both groups. Providing professional learning for both groups also ensured that there were opportunities for collaboration and for the advancement of common language around these foundational principles of learning. The professional learning design also included purposeful modeling of the $e 3$ elements in delivery. The design team felt it was important to not only tell about the model but to also demonstrate strategies for including all three elements in instruction.

The principals and instructional coaches met three times in the first year. The first meeting contained an in-depth introduction to the $e 3$ model, as well as to the content and construct of the new Florida Standards and their associated assessments. The second meeting focused on recognition of the instructional shifts required by the new standards. 
Table 1

Possible sources of evidence for the three essential elements, as determined by participating district teams

\begin{tabular}{|c|c|c|}
\hline & Student Evidence & Teacher Evidence \\
\hline Deeper & - asking content-based questions & - demonstrating the gradual release model \\
\hline Knowledge & $\begin{array}{l}\text { - } \text { reading complex texts, elaborating and } \\
\text { defending ideas while citing evidence } \\
\text { - Students are applying skills and knowledge } \\
\text { - Students are using academic, domain } \\
\text { specific vocabulary } \\
\text { - Students are creating projects, debates, } \\
\text { inquiries, etc... } \\
\text { - engaged in conversations related to the } \\
\text { learning }\end{array}$ & $\begin{array}{l}\text { - encourage students to do the thinking, talking, } \\
\text { and applying } \\
\text { - ask higher order questions and create } \\
\text { scaffolded question ladders } \\
\text { - use scales and rubrics } \\
\text { - share essential questions and have students } \\
\text { demonstrate and refine their thinking } \\
\text { responding to the EQ }\end{array}$ \\
\hline Collaboration & $\begin{array}{l}\text { - conversations are on topic and academic and } \\
\text { domain specific language is used } \\
\text { - peer-to-peer questioning } \\
\text { - all students have a role } \\
\text { - role cards and other tools are utilized to } \\
\text { ensure depth of conversation } \\
\text { - references to text and evidence is being } \\
\text { offered and discussed }\end{array}$ & $\begin{array}{l}\text { - classroom layout promotes collaboration } \\
\text { - student roles and learning tasks are clearly } \\
\text { communicated } \\
\text { - facilitation strategies are being used - teacher } \\
\text { is circulating, asking questions, clarifying, } \\
\text { offering feedback } \\
\text { - project-based learning and inquiry cycles are } \\
\text { embedded in collaborative work }\end{array}$ \\
\hline Engagement & $\begin{array}{l}\text { - on task and on topic conversation } \\
\text { - asking questions } \\
\text { - actively writing, discussing, answering } \\
\text { problems } \\
\text { - exploring multimedia, text, art, } \\
\text { - formulation of products } \\
\text { - self-reflection and self-assessment } \\
\text { - goal setting } \\
\text { - student having their "voices" heard by using } \\
\text { a variety of self-selected tools and resources } \\
\text { to demonstrate knowledge }\end{array}$ & $\begin{array}{l}\text { - circulation around the room and among } \\
\text { students, asking questions, clarifying, and } \\
\text { giving feedback } \\
\text { - caring and respectful of students } \\
\text { - sets high expectations for self and students } \\
\text { - enthusiasm and excitement for the subject, } \\
\text { topic, and activity is demonstrated } \\
\text { - real world connections are clear } \\
\text { - notices when students are disengaged and } \\
\text { redirect }\end{array}$ \\
\hline
\end{tabular}

This focus was accomplished by asking participants to examine their teacher observation framework, an examination that called for them to unpack the elements of the framework for the purpose of determining the "language of proficiency" contained within. Observer recognition of the new standard of proficiency required by the Florida Standards was presented as the first step on the path of helping teachers improve their practice.

Upon establishing the need for recognition of the shifts in instruction required by the Florida Standards, the third and final meeting in the series facilitated the creation of an $e 3$ Action Plan for each school team. In this action plan, principals and instructional coaches mapped out tasks, timelines, and intended outcomes for implementing the $e 3$ model in their schools. Table 1 illustrates a collection of responses gathered from various districts looking at best practices, easy to implement strategies and evidence within each category of the $e 3$.

Figure 2 demonstrates the work done by one of the districts during the sessions to focus guidance, support, and monitoring using Marzano's Teacher Evaluation System. District educators opted to begin their implementation plan for this framework by selecting areas of focus within each of the three elements of the $e 3$ model. As a district team, they then selected Marzano indicators listed below each area to become focus indicators for the year. This process allowed principals and teachers to have input in the process and allowed the school to discern between the 64 indicators to determine their first eleven focus indicators. 


\section{Impact}

In an environment where teacher observation frameworks call for teachers, principals, coaches, and other observers to focus their attention on 60 or more intricate elements of instructional practice, there is a clear need to focus on those elements that make the most difference for students. The $e 3$ model is an attempt to bring that focus to the process of improving instructional practice by concentrating efforts on observers becoming expert at recognizing and giving feedback to the instructional elements of collaboration, deeper knowledge (rigor), and

engagement. Increased observational proficiency in these elements, on the part of administrators and instructional coaches, will result in more reliable and consistent feedback to teachers. This increased reliability and consistency leads to greater credibility with teachers. Feedback that is credible, reliable, and actionable leads to increased teacher proficiency, which naturally leads to improved outcomes for students (Wiggins, 2012).

This focus on the research-based e3 model has been embraced by the eight school districts and 55 schools impacted by the Teacher Incentive Fund (TIF) grant. There have been over 80 participating principals and instructional coaches in the training series, with resulting action plans in each of the participating schools.

\section{Student Outcomes within Schools with the highest rates of e3 implementation.}

Through observations by NEFEC staff and selfreported details from school principals, five schools
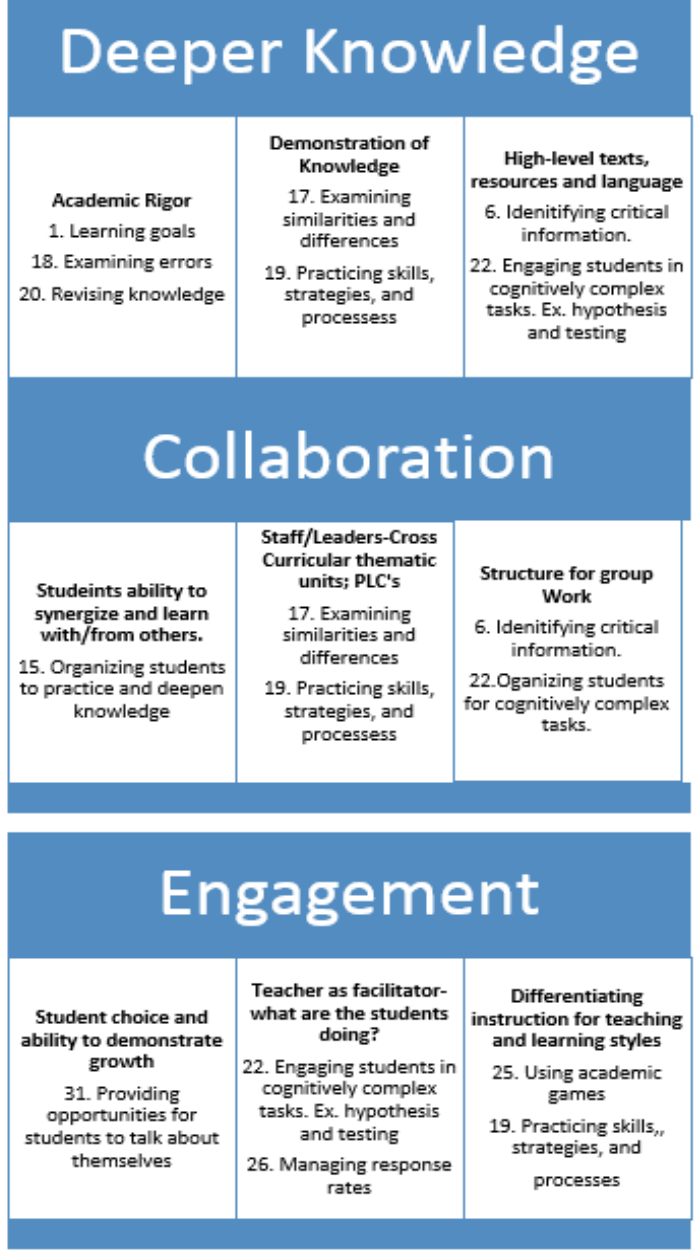

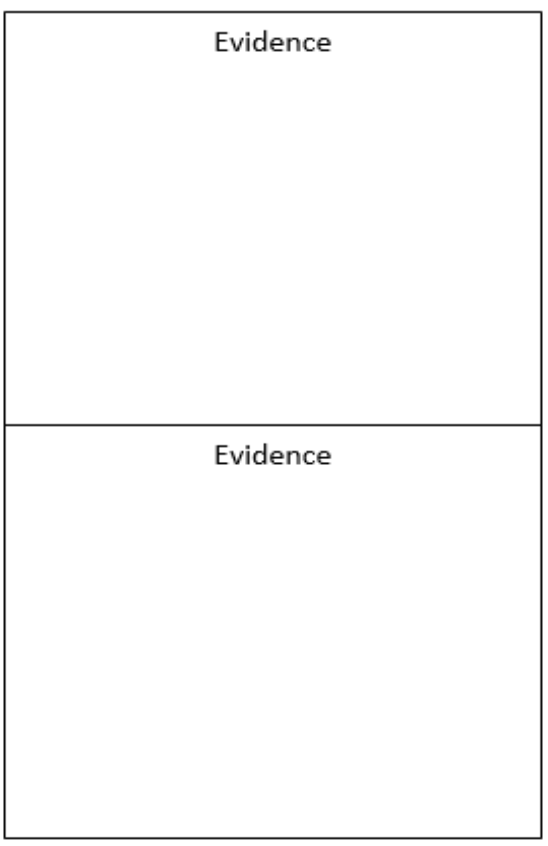

Evidence 
were identified as having the most success implementing the $e 3$ across all teaching and learning practices. These schools used the $e 3$ tools as a guide for teacher lesson planning- requiring teachers to infuse elements of engagement, collaboration and deeper knowledge within all curriculum units. These units were examined by school administration and evidence was documented using the $e 3$ Observation Tool.

Professional development included comprehensive training on how to use the $e 3$ within each content area and school leaders often spotlighted best practices during faculty gatherings. The five schools included three elementary schools, one high school and one middle (6-8) school. These schools were rural schools with significant levels of diversity and all have been designated as Title 1 Schools. Examining the student outcome variables over the course of the data collection period found the following gains:

- $4 \%$ average increase in student attendance

- $11 \%$ average decrease in student discipline referrals

- $5 \%$ increase in teacher attendance

Faculty Outcomes (retention, attendance) within Schools with the highest rates of e3 implementation (e3 schools)

The research also included analysis of the teacher retention rates of the $e 3$ schools with the highest rates of implementation. The trends showed that the schools that implemented the $e 3$ process with input and engagement from the staff saw an average of a $9 \%$ increase in teacher attendance. In these rural districts, those savings equate to an average minimum of $\$ 8,800$ in funds that could be used for additional teaching and learning resources. In addition, the $e 3$ schools showed a collective 5\% increase in teacher retention rates. Teacher feedback from the process highlighted the increased input the administration sought from teachers in the implementation of the new teaching and learning tool, the opportunities to share ideas around the $e 3$ elements with colleagues and the use of a tool that was not evaluative but rather used to enhance teaching and learning delivery, reflection and outcomes.

\section{Practitioner Testimonials}

In addition to the analysis of leading and lagging indicators, the researchers also solicited practitioner testimonials following each professional development session in the form of an exit ticketdescribing how they had been using the $e 3$ resources in their schools and what has been the impact. The findings from these exit tickets demonstrate the ease of implementation of the $e 3$ model as a mechanism to navigate the challenges faced when transitioning to the new standards. Both teachers and administrators shared how these resources have also led to increased student engagement, rigor and in many instances, improved student achievement.

A random sampling of the exit tickets from the e3 schools include:

Principal, Elementary School: We have tied the Essential 3 to our district evaluation tool to make sure we are inspecting what we expect and shifting focus to not just about what the teacher is doing but what the students are doing. When teachers are building lessons we ask them to fidelity check their lessons by asking if they have met all three components of the essential 3. The Essential 3 are all interconnected:

- Collaboration is the method for how students are learning

- Engagement is the interest level and student ownership of what is being learned.

- Higher Rigor is the level of instruction and output of students' knowledge/understanding.

Our scores continue to improve year over year. Improvements in scores are beginning to build teacher confidence and increase their willingness to do more.

Principal, Elementary School; $A$ veteran teacher of 32 years found through unpacking the standards and conversation with a team that she needed to dig deeper in the standards and has since provided lessons that expose her students to the standards through rigorous work and conversations. The teacher and her team have begun to analyze the work provided so the students meet the rigor of the standard.

Principal, Elementary School: The implementation of our new state and district standards has been positively impacted with the infusion of the e3 in our classrooms. The more rigorous and comprehensive tools and resources is a natural facilitator of all of the Essential 3 elements. Brand new teachers and teachers new to our school are embracing the new curriculum, thereby embracing e3.

Teacher, Middle School: We created a culture of high expectations - ensuring the Essential 3 was evident-anywhere from the planning stages, to the instruction, to the student activity, to the student 
outcomes. In grade-level team meetings, even the most seasoned veteran teachers are now saying, "I had plenty of collaboration and engagement before, but I had to go back ask myself, how could I make that a more rigorous lesson." Good stuff!!

Principal, Middle School: I Introduced Essential 3 to faculty in the summer and continue to embed the system in all PD and faculty meetings. We then allowed teachers to visit classrooms to see Essential 3 modeled effectively. Also adapted schedule to allow teachers the time to collaborate and plan Essential 3 embedded lessons. We have seen significant increases student achievement and engagement based on first quarter testing and classroom walkthroughs.

\section{Implications for Policy and Practice}

\section{Educational Practices}

The $e 3$ model serves as a foundational, first-step in the process of rural schools transitioning to more rigorous state and national standards. The format is functional and manageable for educators and school leaders to implement, monitor and collaborate with peers to share best practices in these three universal strategies. The $e 3$ serves as a model of learning for high-needs rural schools when time, resources and funds are a barrier. The non-punitive, collaborative model transcends learning environments, demographics and achievement levels by creating an atmosphere of personalization, teamwork and an opportunity for teachers to facilitate a more rigorous understanding of complex concepts - and not just cover content. Elements of deeper knowledge, collaboration, and engagement within lesson plans and instructional practice become the "lens" through which effective teaching and learning can be seen.

When examining the student impact of the university and rural school district partnership, the data illustrate the influence of professional growth of teachers and increased focus of student collaboration, engagement and deeper knowledge within instructional practices. The five schools implementing the $e 3$ throughout all professional development activities saw gains in attendance and reductions in discipline referrals. Despite not showing gains in student achievement, these variables are leading indicators that may lead to increased achievement over time (Luiselli, J. K., Putnam, R. F., Handler, M. W., \& Feinberg, A. B., 2005). When analyzing the data examining the teacher outcomes, including attendance and retention, similar positive trends emerged. Increased teacher retention and attendance district wide could have a significant impact on more tangible outcomes and gains in terms of both financial and human resourcesoften scarce in high-needs rural districts.

Beyond the content, the implementation practices may serve as an exemplary model based on the high level of interaction between teachers and administration and the adaptability and personalization of the professional learning. The $e 3$ resources and implementation process may also serve as an exemplary model for reaching the needs of high-needs schools when a sense of urgency is coupled with limited resources. As practitioners learn how to infuse the elements of the $e 3$ model, a cadre of teacher leaders helped to document teaching and learning outcomes and share best practices and exemplars via an online portal. This process illustrates the effective strategies for implementation and establishes a network of collaboration of practitioners throughout the state.

Furthermore, when considering the participant program feedback, the $e 3$ professional development tool and process was uniquely effective within the rural context. First, the training sessions were held within the rural school districts. This was advantageous in terms of travel, staffing coverage and it also allowed participants to know that their university partners valued the "regional" context of their home district. Next, simplicity of the $e 3$ tool ensures that it is easy to use and can be implemented on a daily basis, not just during annual evaluations. Finally, the $e 3$ tool and corresponding professional learning series was implemented throughout the school year. Rather than professional learning that takes place when school is not in session over the summer, $e 3$ was part of a job-embedded process where UNF staff were able to work with teachers and administrators throughout the year to support instructional practices, monitor progress and adjust future sessions based on participant feedback. The $e 3$ implementation model is presented in Figure 3.

\section{Educational Policy}

High need rural schools often have unique contextual challenges including high poverty and limitations in terms of community, economic and educational resources (Forner, Bierlein-Palmer, \& Reeves, 2012; Lamkin, 2006). These challenges are compounded when there is a lack of resources to support teachers and administrators as they transition to the new state and national curriculum standards. Recent research showed that nearly half of all states 
cited resource issues as a major challenge to Common Core State Standards implementation and states are facing major challenges in preparing teachers for the new standards (Kober \& Rentner, 2012). States, districts and school-based stakeholders need strategies and best practices to implement these standards and corresponding instructional practices with fidelity- in a manner that is mindful of the economic, training and resource limitations within these high needs areas.

When examining the $e 3$ tool implementation and associated impact, numerous significant implications emerged. By utilizing a teaching and learning tool that was a reflection tool rather than an evaluation, teachers felt they could reflect upon their own practice in a more meaningful and consistent manner. They also felt valued and appreciated when administrators promoted peer collaboration and took the time to hear what professional learning teachers would like to participate in. This opportunity for collaboration and increased engagement was clearly made teachers feel valued, supported and significant in their roles as professionals.

The research will help to inform policies within high needs rural that may contribute to significant and lasting gains in the areas of student achievement, engagement, and collaboration. Even more important, the significant involvement by rural school leaders and practitioners in the development, implementation and research associated with the $e 3$ tool helps to illustrate the authenticity of the tool within the unique, complexities of rural schools. Finally, the simplicity and efficiency of this tool and limited resources needed to implement it with fidelity demonstrate an understanding of the needs of rural teachers, administrators and students throughout the nation.

\section{References}

American Institutes for Research. (2014). The shape of deeper learning: Strategies, structures, and cultures in Deeper Learning Network high schools. Retrieved from http://www.air.org/sites/default/files/downloads/r eport/Report $\% 201 \% 20$ The $\% 20$ Shape $\% 20$ of $\% 20$ Deeper\%20Learning_9-23-14v2.pdf

Appleton, J. J., Christenson, S. L., \& Furlong, M. J. (2008). Student engagement with school: Critical conceptual and methodological issues of the construct. Psychology in the Schools, 45, 369386.

Barron, B., \& Darling-Hammond, L. (2008). Powerful learning: Studies show deep understanding derives from collaborative methods. Edutopia. (October 2008). doi: http://www. edutopia.org/inquiry-projectlearning-research.

Christenson, S.L., Reschley, A.L., \& Wylie, C. (2013). Handbook of research on student engagement. New York: Springer.

Colf, M., \& Harmon, H. (2011). Serving rural school districts and communities: Rethinking the ESA commitment. Perspectives: A Journal of Research and Opinion about Educational Service Agencies, 17, 31-40.

Danielson, C. (2013). The Framework for Teaching Evaluation Instrument. Retrieved from www.danielsongroup.org

Finn, J. D. (1989). Withdrawing from school. Review of Educational Research, 59, 117-142.
Finn, J. D. (1993). School engagement and students at risk. Washington, DC: National Center for Education Statistics.

Florida Department of Education (2012) Teacher evaluation systems alignment: The Florida Educator Accomplished Practices Retrieved April 19, 2018 from http://www.fldoe.org/core/fileparse.php/7503/url t/0071814-tesa-feaps- marzanodanielson.pdf

Forner, M., Bierlein-Palmer, L., \& Reeves, P. (2012). Leadership practices of effective Title 1 superintendents: Connections to Waters and Marzano's leadership correlates. Journal of Research in Title 1 Education, 27(8), 1-13.

Fredricks, J. A., Blumenfeld, P. C., \& Paris, A. (2004). School engagement: potential of the concept: state of the evidence. Review of Educational Research, 74, 59-119.

Glickman, C.D., Gordon, S.P., \& Ross-Gordon, J.M. (2013). Supervision and instructional leadership: A developmental approach $\left(9^{\text {th }}\right.$ edition). Boston: Allyn \& Bacon.

Harmon, H. (2006). Tapping the potential of educational service agencies. The School Administrator, 3(63), 36-41.

Hewlett Foundation. (2012). Deeper learning: Strategic plan summary. San Francisco, CA: Author.

Jimerson, S., Campos, E., \& Grief, J. (2003). Toward an understanding of definitions and measures of 
school engagement and related terms. The California School Psychologist, 8, 7-27.

Jimerson, S., Renshaw, T., Stewart, K., Hart, S., \&

O’Malley, M. (2009). Promoting school completion through understanding school failure: A multi-factorial model of dropping out as a developmental process. Romanian Journal of School Psychology, 2, 12-29.

Johnson, J., Thompson, A., \& Naugle, K. (2009). Place-conscious capacity-building: A systemic model for the revitalization and renewal of rural schools and communities through universitybased regional stewardship. Rural Society, 19(3), 178-88.

Kober, N., \& Rentner, D. S. (2012). Year Two of Implementing the Common Core State Standards: States' progress and challenges. Center on Education Policy.

Klem, A. M., \& Connell, J. P. (2004). Relationships matter: Linking teacher support to student engagement and achievement. Journal of school health, 74(7), 262-273.

Lamkin, M. L. (2006). Challenges and changes faced by Title 1superintendents. The Rural Educator, 28(1), 17-24.

Leithwood, K. A., \& Louis, K. S. (Eds.). (1998). Organizational learning in schools. Swets \& Zeitlinger Publishers.

Luiselli, J. K., Putnam, R. F., Handler, M. W., \& Feinberg, A. B. (2005). Whole-school positive behavior support: effects on student discipline problems and academic. performance. Educational Psychology, 25(2-3), 183-198.

MacNeil, A. J., Prater, D. L., \& Busch, S. (2009). The effects of school culture and climate on student achievement. International Journal of Leadership in Education, 12(1), 73-84.

Marzano, R. (2007). The art and science of teaching: A comprehensive framework for effective instruction. Alexandria, VA: Association for Supervision and Curriculum Development.

Ohlson, M. (2009). Examining instructional Leadership: A Study of school culture and teacher quality characteristics influencing student outcomes. Florida Journal of Educational Administration \& Policy, 2(2), 102124.

Railsback, J. (2004). Increasing Student Attendance: Strategies from Research and Practice. Northwest Regional Educational Laboratory NWREL

Shernoff, D., \& Schmidt, J. (2008). Further evidence of an engagement-achievement paradox among U.S. high school students. Journal of Youth and Adolescence, 37(5), 564-580.

Stephens, E.R., \& Keane, W.G. (2005). The educational service agency: American education's invisible partner. Lanham, MD: University Press of America.

Wiggins, G. (2012). Seven keys to effective feedback. Feedback, 70(1), 10-16

\section{About the Authors:}

Matthew Ohlson, Ph.D. is faculty and the Director of CAMP Osprey: Rural Leadership Mentoring Program in the College of Education and Human Services at the University of Florida. He can be contacted at matthew.ohlson@unf.edu

Jerry Johnson, Ed.D. is a Professor in the College of Community Innovation and Education at the University of Central Florida. He can be contacted at jerry.johnson@ucf.edu

Shane Shope, Ph.D. is an Assistant Professor in the Educational Leadership Foundational and Graduate Studies in Education department at Morehead State University. He can be contacted at s.shope@moreheadstate.edu

Jennifer Rivera, M.Ed. is the Supervisor of Curriculum at Instruction for the North East Florida Educational Consortium (NEFEC). She can be reached at RiveraJ@nefec.org

\section{Suggested Citation:}

Ohlson, M., Johnson, J., Shope, S., \& Rivera, J. (2018). The Essential Three (e3): A university partnership to meet the professional learning needs of rural schools. The Rural Educator, 39(2), 3-12. Retrieved from http://epubs.library.msstate.edu/index.php/ruraleducator 